\title{
Surgical Management of an Unstable Lumbar Fracture-Dislocation-A Case Report
}

\author{
0. Rezaee1, R. Salar ${ }^{*}$, R. Jabari1, A. Shams Akhtari2 \\ ${ }^{1}$ Neurosugery Department, Shahid Beheshti University of Medical Sciences, Tehran, Iran \\ ${ }^{2}$ Emergency Department, Shahid Beheshti University of Medical Sciences, Tehran, Iran \\ Email: amin.may1981@gmail.com
}

Received 30 May 2014; revised 30 June 2014; accepted 29 July 2014

Copyright (C) 2014 by authors and Scientific Research Publishing Inc.

This work is licensed under the Creative Commons Attribution International License (CC BY).

http://creativecommons.org/licenses/by/4.0/

(c) () Op Open Access

\begin{abstract}
The lumbar spine is the most common sites for fractures because of the high mobility of the lumbar spine. A spinal cord injury usually begins with a sudden, traumatic blow to the spine that fractures or dislocates vertebrae. A 32-year-old man presented to us after traffic accident. In our patient, unstable fracture-dislocation of the lumbar spine at the L2-L3 level due to traffic accident occurred. The vertebral bodies were fractured and the anterior dislocation happened without spinal cord injury. The patient was a candidate for an open reduction and internal fixation surgery. The posterolateral approach was performed. After insertion of all the pedicle screws, the rods were transversally placed on L2-L3-L4 vertebral bodies and tightened. The reduction of the dislocations was carried out by pushing downwards (foreside) L2 and L4 vertebras and upwards (backside) L3 vertebrae, simultaneously. After securing the reduction of the dislocations, the rods were opened and placed along the spinal column and tightened. This technique is more effective when the pedicle of fractured vertebrae is intact.
\end{abstract}

\section{Keywords}

Fracture-Dislocations, Lumbar Spine, Posterolateral Approach, Reduction, Fixation

\section{Introduction}

Annually, approximately 160,000 patients sustain spinal column injuries in the United States [1]. The lumbar spine is the most common sites for fractures because of the high mobility of the lumbar spine [2]. Fracture of the lumbar spine can occur whenever forces applied to the lower spinal column exceed the strength and stability of the spinal column unit. Common injuries resulting in fractures of the lumbar spine include fall from a height, motor

*Corresponding author.

How to cite this paper: Rezaee, O., Salar, R., Jabari, R. and Shams Akhtari, A. (2014) Surgical Management of an Unstable Lumbar Fracture-Dislocation-A Case Report. Open Journal of Modern Neurosurgery, 4, 137-141.

http://dx.doi.org/10.4236/ojmn.2014.43024 
vehicle and pedestrian accidents, and penetrating trauma, including gunshot wounds and stabbings [1] [3]. Accidents are the fourth leading cause of death in the United States after heart disease, cancer, and stroke, annually accounting for about 50 deaths per 100,000 populations [4]. Because of the energy required to cause these spinal fractures, patients often have additional injuries that require treatment. The spinal cord may be injured, depending on the severity of the spinal fracture [5]. According to Denis' system, spinal traumas are classified to minor and major injury, based on their potential risks to cause instability. Traumatic fracture-dislocation is a high-energy trauma that is classified into major spinal injuries categories and presents with failure of all three columns under compression, tension, rotation, or shear [6]. In this paper, we report a case of lumbar fracture-dislocation treated with unique surgical technique.

\section{Case Presentation}

A 32-year-old man presented to us after traffic accident. Lateral x-ray was taken of the patient and computed tomography (CT) was performed. The CT scan revealed unstable fracture-dislocation of the lumbar spine at the L2-L3 level (Figure 2, Figure 3). The fractures occurred in the vertebral bodies (Figure 1) while the spinal cord was intact. The dislocation occurred in the anterior direction (Figure 2, Figure 3). The patient was a candidate for an open reduction and internal fixation surgery. After general anesthesia, the patient was positioned prone and placed two rolls lengthwise under the axilla and along the sides of the chest from the clavicle to iliac crests to raise the weight of the body off of the abdomen and thorax. After formal surgical skin preparation, the skin and subcutaneous tissue were opened to expose the transverse processes above and below the fracture site. The neurosurgeon and surgical team agreed on a posterolateral approach for the intraoperative reduction of the dislocation and needed instrumentation. Laminectomy was performed to relieve pressure on the spinal nerves exist L2-L3-L4 vertebral levels. C-arm fluoroscope was used for accurate navigation during lumbar pedicle screw placement. After insertion of all the pedicle screws, the rods were transversally placed on L2-L3-L4 vertebral bodies and tightened. The reduction of the dislocations was carried out by pushing downwards (foreside) L2 and L4 vertebras and upwards (backside) L3 vertebrae, simultaneously. To facilitate the reduction, facet joint can be realized. After securing the reduction of the dislocations, the rods were opened and placed along the spinal column and tightened. A certain amount of curvature is necessary for the rods to lumbar spinal balance. Before tightening the rods, the hip joint of the patient should be extended enough. Postoperative lateral X-ray, CT scan and MRI revealed that surgery was successful and the dislocation was quite reduced (Figure 4, Figure 5). The patient was good and discharged after 3 days.

\section{Discussion}

Traumatic lumbar fracture-dislocations have unique considerations for radiologic assessment, neurologic injury, and acutely deformed anatomy compared with degenerative or chronic deformity. A spinal cord injury usually begins with a sudden, traumatic blow to the spine that fractures or dislocates vertebrae [5]. In our patient,
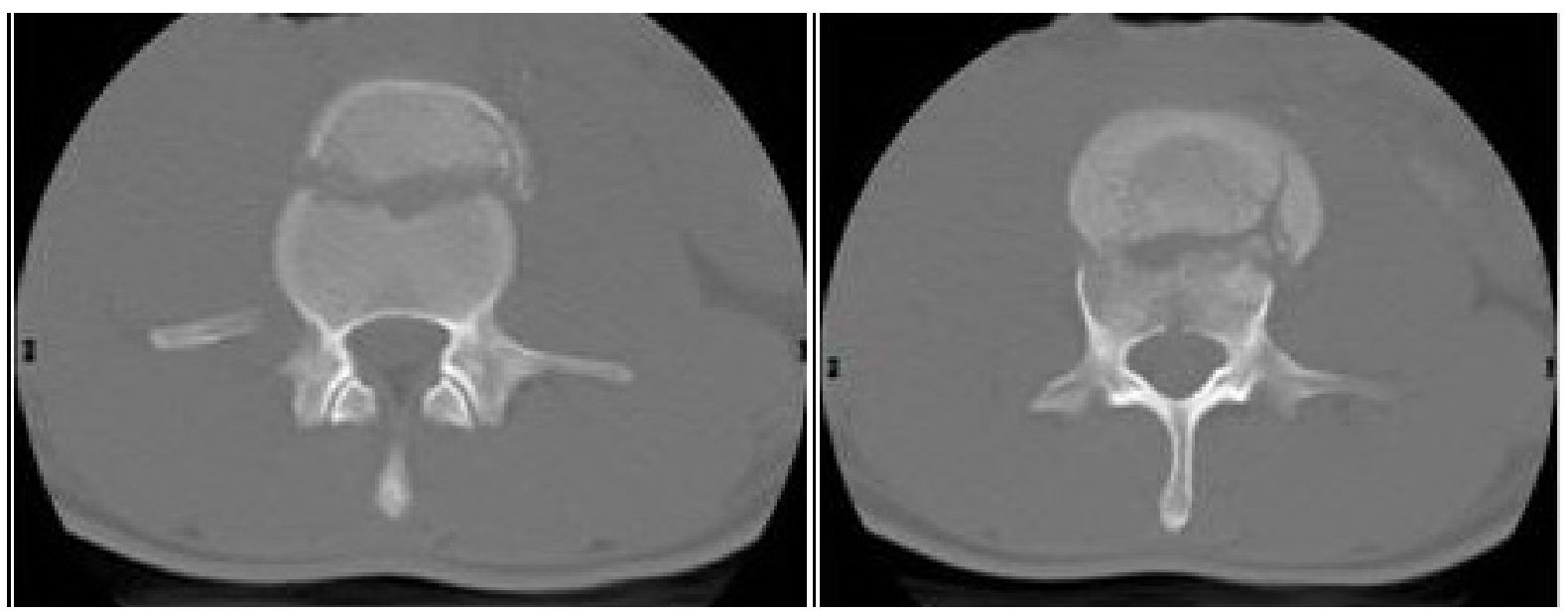

Figure 1. Peroperative axial CT images showing vertebral fracture. 


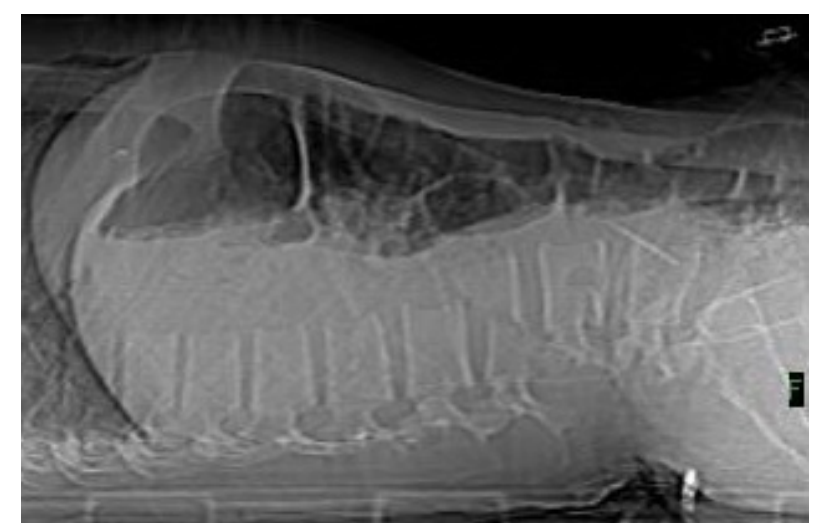

Figure 2. Preoperative supine CT image showing unstable fracture-dislocation of the lumbar spine at the L2-L3 level and anterior deviation of the spinal cord.

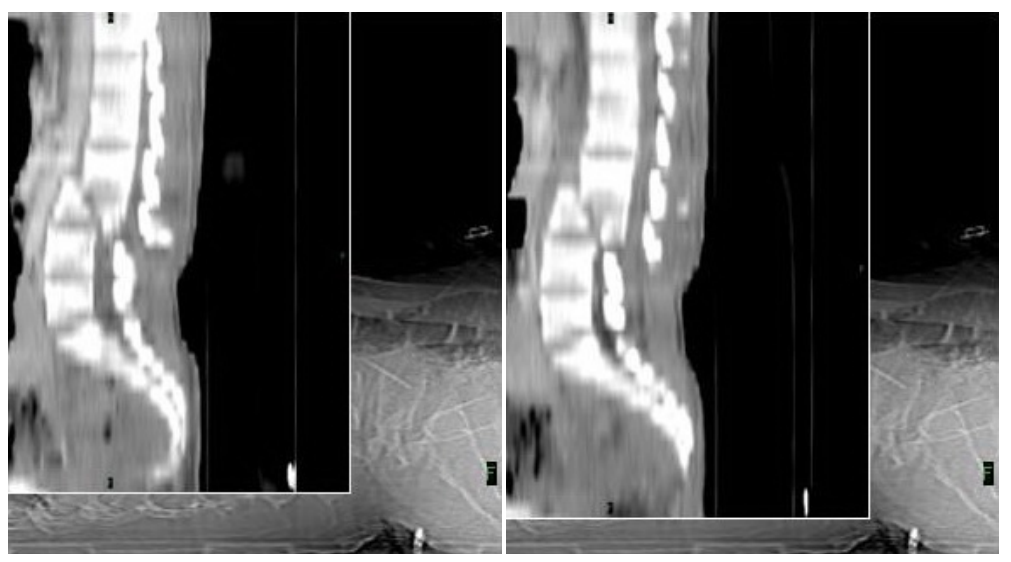

Figure 3. Preoperative reconstructed sagittal CT images showing fracturedislocation of the lumbar spine at the L2-L3 level and anterior deviation of the spinal cord.

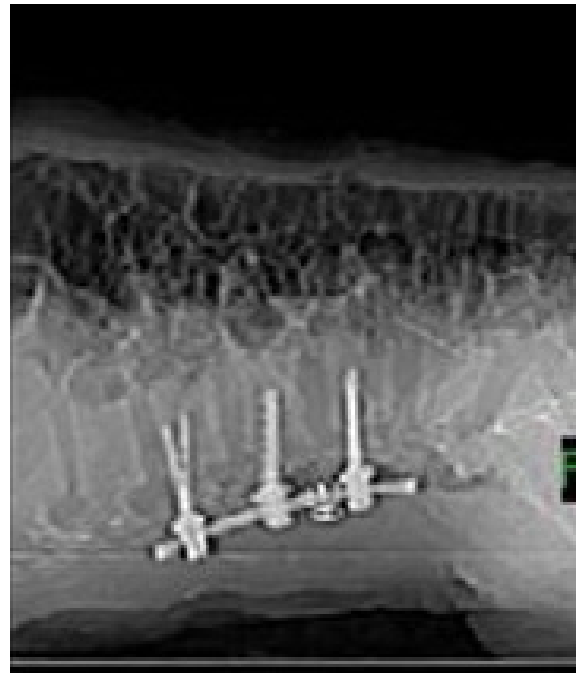

(a)

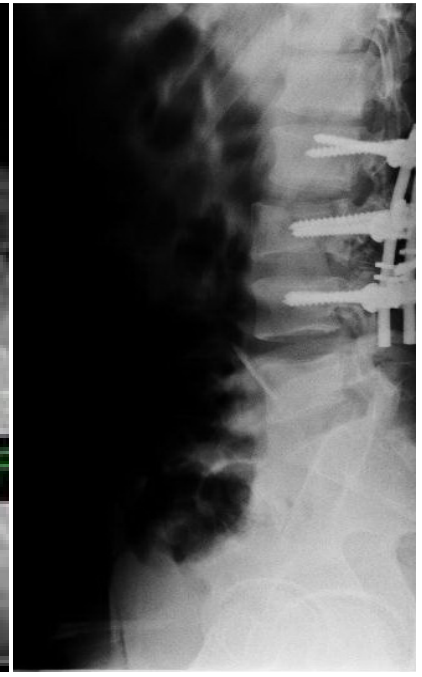

(b)

Figure 4. Postoperative supine CT (a) and lateral X-ray (b) showing satisfactory reduction with good segment alignment. 

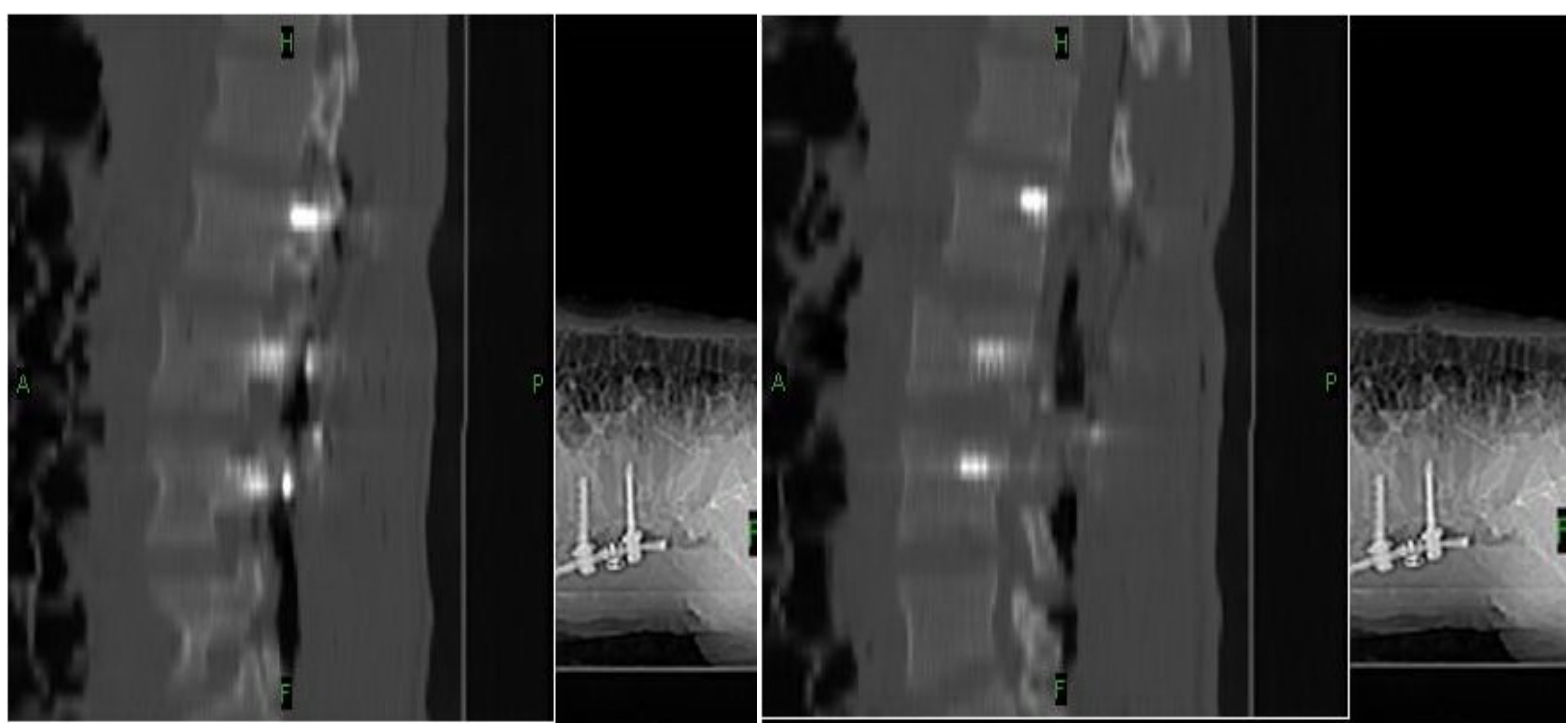

Figure 5. Postoperativereconstructed sagittal CT image showing that the spinal canal is open.

unstable fracture-dislocation of the lumbar spine at the L2-L3 level due to traffic accident occurred. The vertebral bodies were fractured and the anterior dislocation happened without spinal cord injury. The goals of surgical management of unstable lumbar fracture-dislocations include attainment of the normal spinal anatomy, as well as maintenance of reduction, decompression of the neurological structures, and early mobilization [7]. The use of modern technologies makes it possible to completely solve the orthopedic problems in patients with severe spinal injuries [8]. In order to reach instant stability and avoid using postoperative rigid external support, the internal fixation was recommended by many surgeons in recent years [2] [9]. The patient underwent open reduction and internal fixation surgery. Significant progress in surgical treatment of lumbar spine injuries has been made over the past decade. The surgeon chooses the treatment method based on the severity of injury and the optimal method for treating this category of patients is to possibly solve all the problems during a single surgery [8]. We used posterolateral approach in this surgery. The posterolateral approach provides direct access to the transverse processes and facet joint through a longitudinal paraspinal incision, retracting the erector spinal muscles medially [10] [11]. Our technique in this surgery is more effective when the pedicle of fractured vertebrae is intact. By this method, the treatment of unstable fracture-dislocation lumbar spine will be successfully performed.

\section{References}

[1] Xiong, W., Li, F., Zhang, F., Huo, X. and Chen, A. (2013) Single-Stage Operation for Traumatic Thoracolumbar Fractures with Severe Dislocation via a Posterior Approach Alone: A Case Series. Turkish Neurosurgery, 23, 170-178.

[2] Levi, A.D., Hurlbert, R.J., Anderson, P., et al. (2006) Neurologic Deterioration Secondary to Unrecognized Spinal Instability Following Trauma-A Multicenter Study. The Spine Journal, 31, 451-458. http://dx.doi.org/10.1097/01.brs.0000199927.78531.b5

[3] Bernstein, M.P., Mirvis, S.E. and Shanmuganathan, K. (2006) Chance-Type Fractures of the Thoracolumbar Spine: Imaging Analysis in 53 Patients. American Journal of Roentgenology, 187, 859-868. http://dx.doi.org/10.2214/AJR.05.0145

[4] Hsieh, C.T., Chen, G.J., Wu, C.C. and Su, Y.H. (2008) Complete Fracture-Dislocation of Thoracolumbar Spine without Paraplegia. American Journal of Emergency Medicine, 26, 633-e5-7.

[5] Holdsworth, F.W. (1963) Fractures, Dislocations and Fracture-Dislocation of the Spine. The Journal of Bone and Joint Surgery, 45, 6-20.

[6] Denis, F. (1984) Spinal Instability as Defined by the Three-Column Spine Concept in Acute Spinal Trauma. Clinical Orthopaedics and Related Research, 189, 65-76.

[7] Moon, M.S., Choi, W.T., Moon, Y.W., Kim, Y.S. and Moon, J.L. (2003) Stabilisation of Fractured Thoracic and Lumbar Spine with Cotrel-Dubousset Instrument. Journal of Orthopaedic Surgery and Research, 11, 59-66. 
[8] Vetrile, S.T. and Kuleshov, A.A. (2004) Surgical Treatment for Thoracic and Lumbar Spine Fractures with Modern Technologies. The Spine Journal, 3, 33-39.

[9] Tan, M., Wang, H., Jiang, X., Yi, P., Wei, H., Yang, F., Wang, W. and Zhang, G. (2007) Screw Fixation via Diploic Bone Paralleling to Acciput Table: Anatomical Analysis of a New Technique and Report of 11 Cases. European Spine Journal, 16, 2225-2231. http://dx.doi.org/10.1007/s00586-007-0500-1

[10] Schmidt, M.H., Larson, S.J. and Maiman, D.J. (2004) The Lateral Extracacitary Approach to the Thoracic and Lumbar Spine. Neurosurgery Clinics of North America, 15, 437-441. http://dx.doi.org/10.1016/j.nec.2004.04.007

[11] Shen, F.H., Marks, I., Shaffrey, C., et al. (2008) The Use of an Axpandable Cage for Corpectomy Reconstruction of Vertebral Body Tumors through a Posterior Extracavitary Approach: A Multicenter Consecutive Case Series of Prospectively Followed Patients. The Spine Journal, 8, 329-339. http://dx.doi.org/10.1016/j.spinee.2007.05.002 
Scientific Research Publishing (SCIRP) is one of the largest Open Access journal publishers. It is currently publishing more than 200 open access, online, peer-reviewed journals covering a wide range of academic disciplines. SCIRP serves the worldwide academic communities and contributes to the progress and application of science with its publication.

Other selected journals from SCIRP are listed as below. Submit your manuscript to us via either submit@scirp.org or Online Submission Portal.
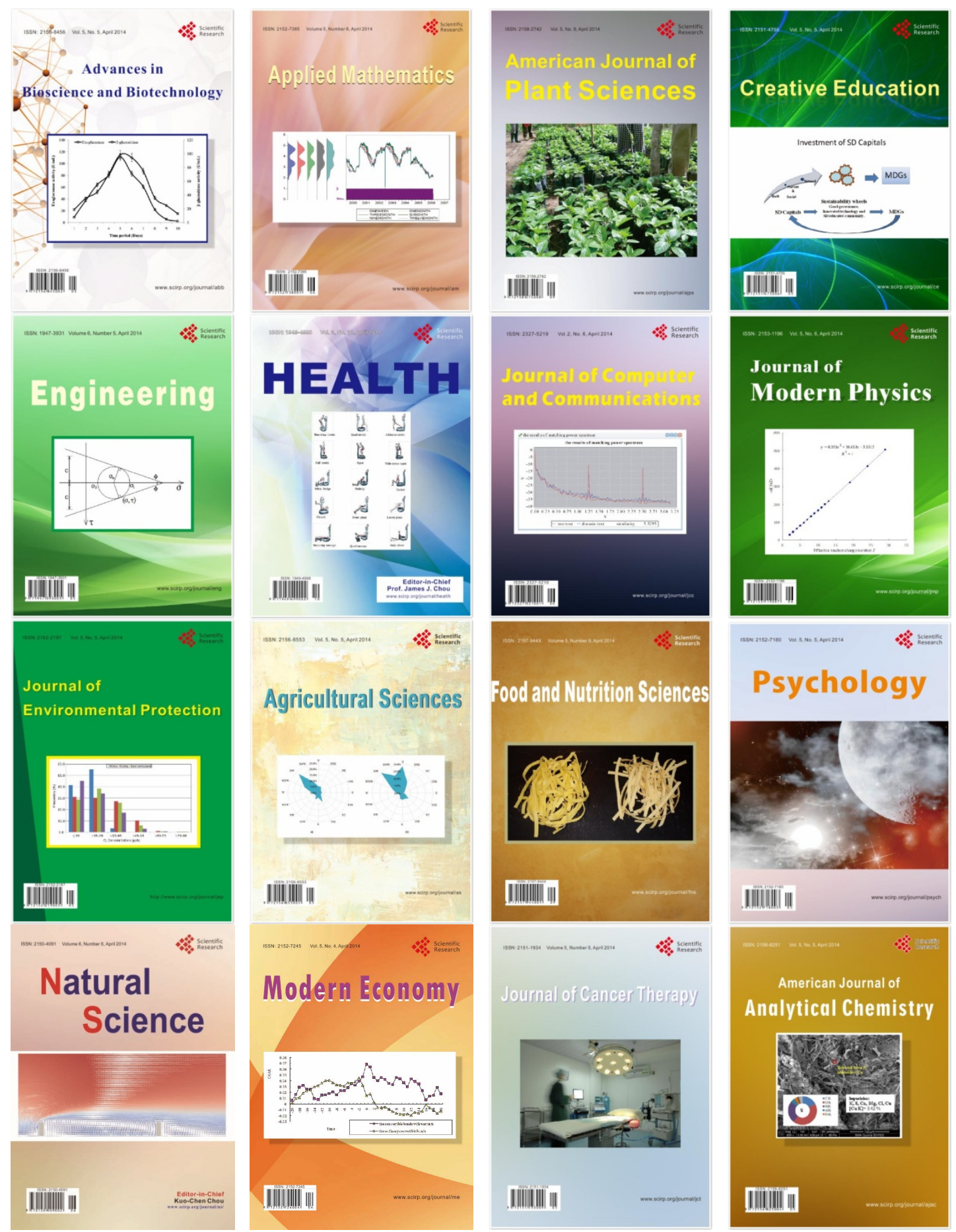